\title{
Creatinine calibration in NHANES: is a revised MDRD study formula needed?
}

\author{
Pierre Delanaye, $\mathrm{MD}^{1}$; Etienne Cavalier, $\mathrm{MD}^{1}$; Nicolas Maillard, $\mathrm{MD}^{2}$; Jean-Marie Krzesinski, $\mathrm{MD}, \mathrm{PhD}^{1}$; \\ Christophe Mariat, $\mathrm{MD}, \mathrm{PhD}^{2}$ \\ ${ }^{I}$ University of Liège, CHU Sart Tilman, Liège, Belgium \\ ${ }^{2}$ University of Saint Etienne, Hopital Nord, Saint Etienne, France
}

\section{To the Editor:}

Selvin et al recently published a study in $A J K D$ concerning the calibration of serum creatinine in the National Health and Nutrition Examination Survey (NHANES). ${ }^{1}$ Calibration of creatinine is important for precise results when using the Modification of Diet in Renal Disease (MDRD) Study equation, especially when calculations involve low creatinine values. ${ }^{1-3} \mathrm{~A}$ re-expressed version of this equation, generated with an isotope dilution mass spectrometry-traceable method (Roche Diagnostic, Indianapolis, IN), has been proposed, in which the factor 186 is replaced by 175 after calibration. ${ }^{4}$ However, the way this new factor has been obtained seems questionable. ${ }^{5}$ The authors have modified their equation after having recalibrated their Jaffé creatinine (Beckman CX3, Beckman Coulter, Inc, Fullerton, CA) to the enzymatic method on 40 reference sera with creatinine values between 0.5 and $5 \mathrm{mg} / \mathrm{dL}\left(44-442 \mu \mathrm{mol} / \mathrm{L}\right.$; see Fig 3 of ${ }^{5}$ ). From our point of view, the range of creatinine used for the calibration appears to be too large because the calibration effect on the MDRD Study results is only relevant in the lower values of creatinine ( 0.5 to $2 \mathrm{mg} / \mathrm{dL}$ [44-177 $\mu \mathrm{mol} / \mathrm{L}]){ }^{3}$ Within this specific range (Fig 3 of $^{5}$ ), the slope is closer to 1 (and not to 0.906 , as is the case if higher values are included). ${ }^{5}$ Accordingly, Selvin et al's data clearly showed a slope of 1 between creatinine values measured with the enzymatic and the Beckman Jaffé methods used in the 2001-2002 and 2003-2004 NHANES. In Selvin et al's study, mean creatinine values used for calibration are in the critical range $(0.982$ and $0.977 \mathrm{mg} / \mathrm{dL}$ [ 87 and $86 \mu \mathrm{mol} / \mathrm{L}]){ }^{1}$ Thus, factor correction should be precisely recalculated for this range, but based on the data from both Levey et al and Selvin et al, ${ }^{1}$ the "new" factor would certainly be higher than 175.

\section{Acknowledgements}

Support: None.

Financial Disclosure: None.

\section{References}

1. Selvin E, Manzi J, Stevens LA, et al: Calibration of serum creatinine in the National Health and Nutrition Examination Surveys (NHANES) 1988-1994, 1999-2004. Am J Kidney Dis 50:918-926, 2007

2. Delanaye P, Cavalier E, Krzesinski JM, Chapelle JP: Why the MDRD equation should not be used in patients with normal renal function (and normal creatinine values)? Clin Nephrol 66:147-148, 2006

3. Murthy K, Stevens LA, Stark PC, Levey AS: Variation in the serum creatinine assay calibration: a practical application to glomerular filtration rate estimation. Kidney Int 68:1884-1887,2005

4. Levey AS, Coresh J, Greene T, et al: Using standardized serum creatinine values in the modification of diet in renal disease study equation for estimating glomerular filtration rate. Ann Intern Med 145:247-254, 2006

5. Levey AS, Coresh J, Greene T, et al: Expressing the Modification of Diet in Renal Disease Study equation for estimating glomerular filtration rate with standardized serum creatinine values. Clin Chem 53:766-772, 2007 
Published in: American Journal of Kidney Diseases (2008), vol. 51, iss. 4, pp. 709; author reply 709-10. Status: Postprint (Author's version) 